\title{
XL. On apparatus for the circular polarization of light in liquids
}

Rev. Baden Powell M.A. F.R.S.

To cite this article: Rev. Baden Powell M.A. F.R.S. (1843) XL. On apparatus for the circular polarization of light in liquids, Philosophical Magazine Series 3, 22:145, 241-245, DOI: 10.1080/14786444308636370

To link to this article: http://dx.doi.org/10.1080/14786444308636370

册 Published online: 01 Jun 2009.

Submit your article to this journal $\lceil\pi$

Џ Article views: 3

Q View related articles $\asymp$ 
THE

LONDON, EDINBURGH AND DUBLIN

PHILOSOPHICAL MAGAZINE

AN D

JOURNAL OF SCIENCE.

[THIRD SERIES.]

$A P R I L 184.3$.

XL. On Apparatus for the circular Polarization of Light in Liquids. By the Rev. Baden Poweld, M.A., F.R.S., \&c., Savilian Professor of Geometry, Oxford*.

THE subject of circular polarization developed in light in passing through certain substances, especially liquids, is one which has at the present day attracted considerable attention, not merely among those who study the properties of light as such, but also among chemists, as supplying a test of the existence of certain elements in the solutions which exhibit it. It has thus become an object of importance to devise means for facilitating the performance of the observations by which the existence of this property is detected and its amount measured.

The general nature of all methods and apparatus for this purpose must be obvious on the first conception of the property itself. But they may admit of considerable modifications in their details, so as to be more or less applicable under different conditions.

The most ample details as to the methods of experimenting have been given by the original discoverer of their singular phænomena, M. Biot, in several memoirs in the Annales de Chimie + ; he has also devised a most complete and accurate apparatus for the purpose, which may be procured from Paris made under his direction. Without in the slightest degree meaning to disparage the excellence of that apparatus, or indeed the necessity for it in all refined and accurate researches, yet for the more general purposes of the chemical inquirer, and especially for students, it must be allowed that its complexity, difficulty of adjustment, and expense must stand much

* Communicated by the Author.

[ + See also Taylor's Scientific Memoirs, vol.i. p. 584 and p. 600. ED.]

Phil. Mag. S. 3. Vol. 22. No. 145. April 1843. R 


\section{The Rev. Prof. B. Powell on Apparatus for the}

in the way of its general introduction. Under this impression, derived in some measure from my own experience, it occurred to me to examine in what respects it might be capable of simplification.

Following up this idea, after many trials I succeeded in contriving an apparatus, which, at least for all general objects, answers the purpose, and is of extremely simple, easy, and cheap construction; requiring in fact little more materials for its several parts than are either to be found already in the laboratory of every chemist, or may be readily procured, or constructed by the most ordinary workman. Of such a contrivance I gave a short account to the Chemical Section of the British Association at the Manchester Meeting, 1842, and a short description with a sketch representing the principle, is given in the reports of the Association for that year.

It has appeared desirable however to offer, to those interested in the subject, some further details, as many may wish to be able to construct such an apparatus for themselves; and still more, as there are one or two improvements in thedetails which have suggested themselves since I gave the description just referred to. I proceed therefore to describe more precisely the principle of the construction as well as its details.

In the construction of $\mathrm{M}$. Biot, the object viewed is the round disc of polarized light transmitted through the aperture of the diaphragm in the tube of the polarizer; in order to see this distinctly through a considerable thickness of liquid; it is indispensable that the liquid be contained in a tube having parallel ends of plate-glass. Such a tube of course requires to be constructed accurately; the necessary supply of them of different lengths, and for comparative experiments, \&c., is expensive; and there is a considerable difficulty in filling them, and fitting on the glass ends so as to exclude airbubbles, \&c. Again, the double-refracting prism, which is necessary to procure a separation of the two images, must be of the most accurate construction, so as to give images absolutely free from colour from refraction, in order to distinguish precisely the tints developed by the polarization.

The main principle of my construction refers to both these sources of difficulty : with respect to the first, I employ common test tubes without any other mode of termination than that furnished by the rounded bottom of the tube, however irregular, and the level surface of the liquid at the top, the tube being necessarily placed in a vertical position. Through such a tube however the image of the disc of polarized light will obviously be very irregular, even if the liquid be perfectly transparent; and no distinct image is seen if it be only 
semi-transparent; so that the double refracting prism cannot be applied to the analysis of it. But this difficulty is at once provided for, and the compound achromatized prism dispensed with, by the very simple eye-piece which I have adopted; for the use of which the fluid need not be absolutely transparent if it only allows a sufficient quantity of light to pass.

This eye-piece consists simply of a rhomb of calc spar in its natural state, the light being admitted through a small hole in the end or bottom of the short tube which contains it, of such a size, relatively to the thickness of the crystal which the light traverses, that the two emergent images of the hole shall not overlap each other; this is easily found by trial; as however these images may be too small readily to follow the changes of tint in them, I magnify them by a lens of short focus fitted in a short tube sliding in the upper part of that containing the rhomb. It only remains to attach to the tube a graduated rim which can turn with it in an outer cell which is attached to the stand of the apparatus, and on which changes in azimuth, or the arcs of rotation of the rhomb about the ray, are measured.

By the arc necessary to be revolved through, by the rhomb, in order to make the extraordinary image come to its minimum, as compared with the position for that effect, when no liquid is interposed, it is, that we estimate the rotatory power of the liquid.

In the eye-piece thus constructed, it will be evident that the object at which we look is the small hole at the bottom of the rhomb. So long then as enough light enters that hole it is immaterial how irregular the refractions of it may be in passing through the tube before it reaches the hole : we are independent of the distinctness of the image which it transmits, and the only material point is the intensity of light which the liquid allows to pass; and this is in fact one of the chief difficulties we have to contend with in these experiments; since many solutions which appear sufficiently transparent in small thicknesses are by no means so when we come to thicknesses of 12 inches or more.

In my first construction the polarizing part of the apparatus consisted of a simple plate of glass inclined $35 \frac{1}{2}^{\circ}$ to the axis of the tube, and in order to have the polarized ray vertical, it was necessary to throw the light on this reflector by means of a small silvered mirror.

In this part, however, I find it a most material improvement to substitute a Nicol prism for the plate of glass; this of course has its axis coincident with that of the tube, and the small R 2 
silvered mirror is placed beneath it, supported in such a manner as to be easily inclined, so as to throw the light in a proper direction. The great advantage gained is the saving of light, of which of course much is lost in the reflexion at the glass: and as a considerable number of the solutions we wish to examine are but imperfectly transparent, this saving becomes important.

In order to determine the direction of rotation, or the right or left-handedness of the polarization, it is necessary to compare two different thicknesses of the liquid: in other instances it is interesting to compare the effects of two different liquids : for these purposes it is extremely convenient to have a contrivance by which two tubes can be brought in succession into the apparatus without deranging the adjustment of the other parts.

For different fluids different lengths of tube are required; for some highly energetic, as oil of turpentine, with a length of 5 or 6 inches tints are seen; with most, solutions of sugar, \&c., from 12 to 18 or even 24, inches are necessary. Hence the apparatus should be so contrived as to admit of the eyepiece being slid up and down as occasion requires.

All these conditions are fulfilled in the construction of which I annex a sketch for the convenience of those who may wish to construct similar ones; and of which the following few details will abundantly suffice for explanation.

Fig. 1. gives a general perspective view of the whole in its latest form. Fig. 2. is the lower part according to the first construction. $(\mathrm{P})$ is the polarizing part, $(\mathrm{A})$ the analysing.

In each of these figures $(s)$ is the silvered mirror which first receives the ray (either from a flame or the sky), which is thence thrown on the polarizer $(p)$, which in fig. 1 is a Nicol prism fitted into the hole $(q)$ in fig. 2, a plain glass reflector inclined $35 \frac{1}{2}^{\circ}$ to the axis, the mirror (s) being capable of inclination to bring the ray into the proper direction. In fig. 1. the course of the ray is represented by the dotted line, when no medium is interposed, from its first reflexion, through the analyser, to the eye $(e)$. A section of the analyser is given in fig. 3 , in which $(r)$ is the rhomb, $(l)$ the lens, and $(k)$ the small hole in the bottom of the short tube or box containing the rhomb: $(m)$ is the section of the circular rim with verniers at the openings $(v, v)$, through which the graduation on the circle $(n)$ beneath is read. The circle $(m)$ is moved round with the tube by means of its milled edge $:(n)$ is fixed to the stand. The arm of the stand $(\mathrm{H})$ which carries $(\mathrm{A})$ should be capable of moving up and down according to the height of the tubes employed, and of being fixed by a clamping 


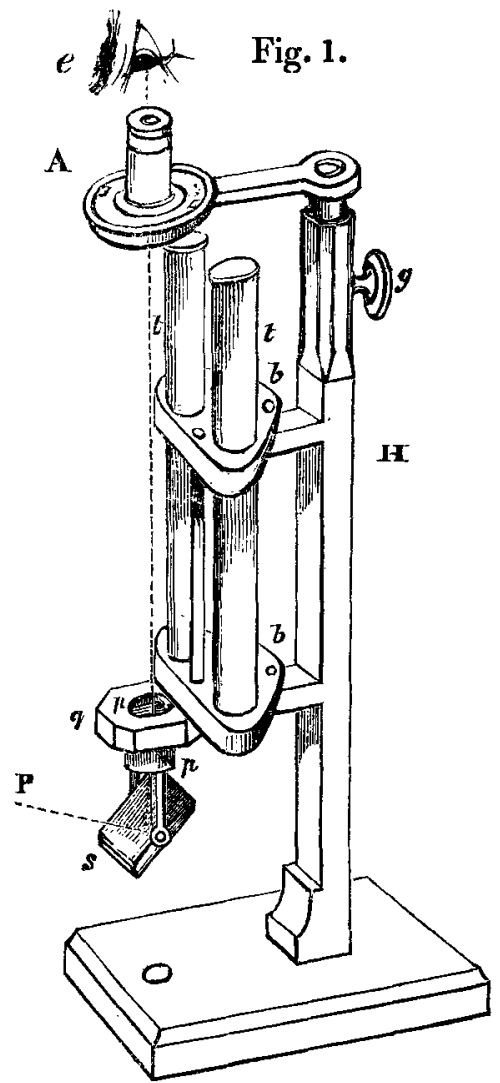

screw $(g)$. The part carrying the tubes $(t t)$ consists of a frame holding them in a vertical position, each tube being inclosed in an opake case. The whole frame with the tubes is made to turn about the pivots $(b b)$, so that either tube in succession can be brought over the hole $(q)$, and with its axis in the line of the ray. Fig. 4 is a section of one of the tubes in its opake covering, to show the manner of its fitting into the frame at the bottom, in which the opening is cut so as just to allow the tube to rest against its edges, and to leave an opening as large as the area of the polarizer.

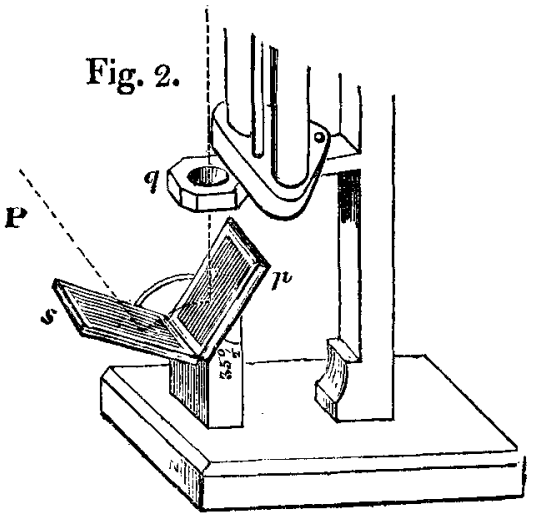

Fig. 3.

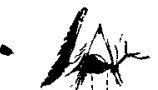

A.

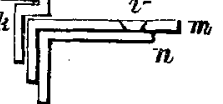

Fig. 4.

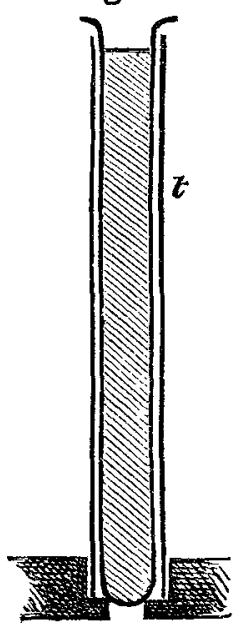

